\title{
Dinoprostone Use and Rupture of Uterus in Primigravida: A Report of Two Cases
}

\author{
Upadhyaya I \\ Paropakar Maternity and Women's Hospital, Thapathali
}

Two cases of complete and incomplete uterine rupture following the use of dinoprostone gel for induction of labor (IOL) at 41 weeks of pregnancy in primigravidas; one of the two being diagnosed after vaginal delivery is presented herewith to alert cautious use of this important agent.

Keywords: Dinoprostone gel, induction of labour, ruptured uterus

\section{INTRODUCTION}

Rupture of pregnant uterus is one of the most serious obstetrical emergencies requiring prompt diagnosis and management, as it is a catastrophic complication, associated with high rates of maternal as well as fetal morbidity and mortality. Most cases of uterine rupture occur in women with a previous cesarean delivery. In fact, primigravid uterus has been considered almost immune to rupture. Prompt recognition of uterine rupture and expeditious recourse to laparotomy are critical in influencing perinatal and maternal morbidity. Two cases of rupture of primigravid uterus following use of dinoprostone for induction of labour are presented here.

\section{CASE}

Case 1: A 23 year primigravida at 41 weeks pregnancy with Bishop score 4 had undergone induction of labor with dinoprostone $(0.5 \mathrm{mg})$ introduced in posterior fornix 2 doses 6 hours apart. Augmentation of labour with 2.5 units Oxytocin was started after 12 hours of last dose of dinoprostone. She developed moderate uterine contractions. Two hour later, she was found pale, pulse rate $100 \mathrm{bp} / \mathrm{m}, \mathrm{BP} 90 / 60 \mathrm{~mm}$ of $\mathrm{Hg}$. Abdominal examination revealed severe tenderness specially at fundal region of uterus and absent fetal heart sound. Vaginal examination revealed moderate amount of fresh bleeding and presenting part was not felt through the cervical os whereas previous examination recorded vertex at minus 1 station. With Suspision of uterine repture and USG
Confirmation on opening abdomen uterine rupture with expulsion of the fetus and placenta into the peritoneal cavity was found. Complete rupture of the uterus from right lateral side of fundus extending up to the cervix was noticed. About $500 \mathrm{ml}$ of blood clots and a liter of hemoperitoneum was found in the peritoneal cavity.

Uterine rupture was repaired in 2 layers. Four units of whole blood was transfused. Baby was fresh still born male $2.9 \mathrm{~kg}$. Post operative recovery was uneventful and the patient was discharged on 7th post operative day (Figure 1 and 2).

Case 2: A 29 year primigravida at 41 weeks pregnancy with Bishop score 4 was admitted for induction of labour. Dinoprostone $(0.5 \mathrm{mg})$ was introduced in posterior fornix 2 doses 6 hours apart. After 8 hours of 2 nd dose Dinoprostone she developed mild uterine contractions. Abdominal examination showed cephalic presentation $3 / 5$ th palpable and fetal heart sound $144 / \mathrm{m}$. Vaginal examination revealed cervical os $5 \mathrm{~cm}$ dilated, cervix $70 \%$ effaced, and vertex at -1 station, membrane ruptured spontaneously. Four hours later labor was augmented with 2.5 units Oxytocin. Three hours later she delivered a male baby of $2.9 \mathrm{~kg}$, with apgar score $1 / 10,3 / 10$, placenta was delivered by controlled cord traction. After removal of the placenta, there was uncontrollable bleeding. She was taken to operation theatre with suspicion of rupture uterus while compression of abdominal aorta was undertaken to control the bleeding.

\section{CORRESPONDENCE}

Dr. Indira Upadhyaya, MD

Paropakar Maternity and Women's Hospital,

Kathmandu, Nepal

Phone : 9851074598

Email: drindira@hotmail.com 


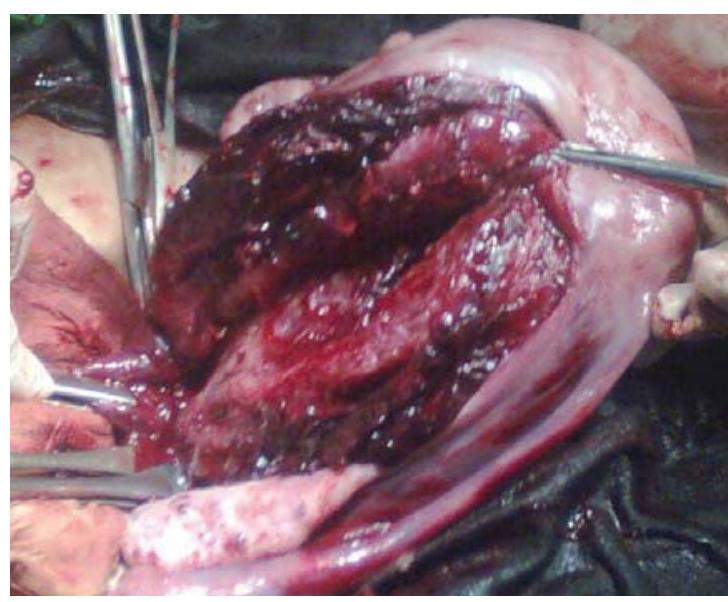

Figure 1. Picture showing side of the rupture uterus

On laparotomy, incomplete rupture was detected at right side of the uterus below the insertion of ovarian ligament upto the lower segment with intact peritoneum. There was a large broad ligament haematoma on the right side. Peritoneum was opened to evacuate the hematoma and tear repaired. Ten units of whole blood and 3 units of fresh frozen plasma were transfused. Post operative recovery was uneventful and she was discharged on 12th post operative day. The baby died on 4th day due to hypoxic encephalopathy grade III.

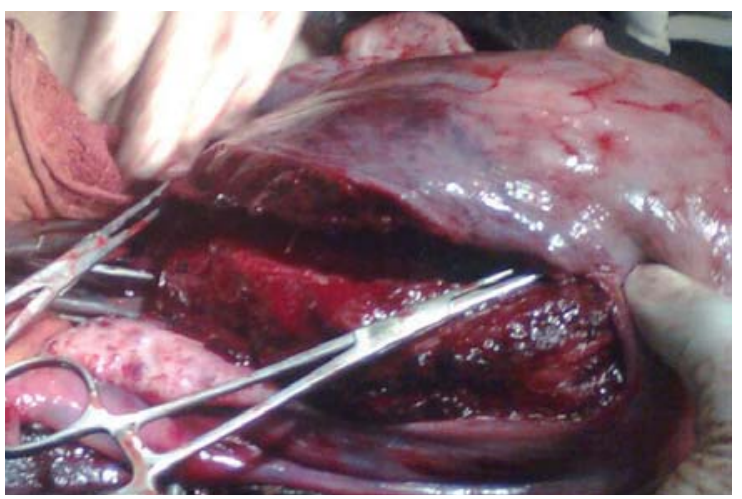

Figure 2. Repairing of the rupture of uterus

\section{COMMENT}

Prostaglandins are now increasingly being used in the management of labour. One of them is Dinoprostone $0.5 \mathrm{mg}$ gel which has local cervical effect in initiating softening, effacement, and dilatation of cervix. It is mainly used with aim of cervical ripening followed by augmentation of labour and vaginal delivery in a woman with poor Bishop score at or near term.1,2 Dinoprostone cervical gel is rapidly absorbed with peak plasma concentrations in 30-45 minutes.

A study done in Eastern Nepal among 126 cases of uterine rupture, lateral wall involvement was significantly higher in the unscarred uterus similar to this study where both cases had lateral wall rupture.3 Provision of adequate staff support in heavy workload situations, continuous surveillance, cardiotocograph and use of tocolytics to overcome strong sustained contraction has big role to prevent the situation. Use of Dinoprostone for cervical ripening followed by augmentation of labour with Oxytocin was the possible factor contributing to rupture uterus. Concomitant use of Dinoprostone and Oxytocin is not recommended. This brings to forefront the need of careful monitoring while using prostaglandin and Oxytocin. One should never forget that the individual response to particular drug is not known. As literature reports Oxytocin-induced rupture of the primigravid uterus is too rare.4,5 The most common risk factors are previous uterine surgery, and most of uterine rupture occurs in women with a previous cesarean delivery but now a days iatrogenic rupture uterus are also reported frequently.

Prompt resuscitation and surgical intervention are the mainstays of the treatment of uterine rupture once the diagnosis is made. The surgical management of uterine rupture should be individualized. The type, extent and location of rupture, the patient's clinical condition, age, parity and number of living children should be taken into consideration. Also the presence of infection, availability and experience of the surgeon are crucial. Easiest and shortest procedure should be attempted in each case. In both of our cases, all these factors were taken into consideration and only repair was done. Acute blood loss, asphyxia and sudden expulsion of fetus into the abdominal cavity during the rupture of the uterus resulted in immediate fetal death in first case whereas neonatal death occurred on third postpartum day in second case due to severe birth asphyxia, similar fetal outcomes were reported in other studies too.6- 8

\section{CONCLUSIONS}

Uterine rupture, a devastating and catastrophic complication can be minimized if prostaglandin and Oxytocin are used with caution. Uterine rupture in primigravida is a rare event, but results in increased morbidity and mortality of the mother and child.

\section{REFERENCES}

1. Induction of labor: RCOG guideline. Evidence-based Clinical Guideline No. 9. London: RCOG;2001.

2. Thavarasah AS, Achanna KS. Uterine Rupture with the use of cervagem (Prostaglandin E1) for induction of labour on account of intra-uterine death. Singapore Med J.1988;29(4):351-2.

3. Chuni N. Analysis of uterine rupture in a tertiary center in eastern Nepal: Lessons for obstetric care. The Journal of Obstetrics and Gynaecology Research.2006;32:574-9.

4. Aboyeji AP, Ijaiya M-DA, Yahaya UR. Ruptured uterus: A study of 100 consecutive cases in Ilorin, Nigeria. The Journal of Obstetrics and Gynaecology Research.2001;27:341-8.

5. Walsh CA, Baxi LV. Rupture of the primigravid uterus: A review of the literature. Obstet Gynecol Surv.2007;62(5):327-34.

6. Seffah JD. Ruptured uterus and the partograph. Int'l Journal of Gynecol and Obstet.2003;80:169-72.

7. Daw E. Oxytocin-induced rupture of the primigravid uterus. The Journal of Obstetrics and Gynaecology of the British Commonwealth $.1973 ; 80: 374-5$.

8. Arora M. Retrospective study of cases of rupture uterus. Obs and Gynae Today.2009;14:123-5. 